\title{
Políticas públicas, gênero e trabalho
}

\author{
JORDÃO HORTA NUNES \\ Professor da Universidade Federal de Goiás \\ jordao_nunes@uol.com.br \\ LuIZ MeLlo \\ Professor da Universidade Federal de Goiás \\ Coordenador do Núcleo de Estudos e Pesquisas em Gênero e Sexualidade - Ser-tão \\ luigman@gmail.com \\ Revalino Antonio de Freitas \\ Professor da Universidade Federal de Goiás \\ Coordenador do Núcleo de Estudos sobre o Trabalho (Nest) \\ freitas@fchf.ufg.br
}

$\mathrm{O}$ ESTUDOS SOBRE o TRABALHO constituem uma importante temática de pesquisa nas ciências sociais, desde seus primórdios, com abrangência mundial. Destaca-se, nesse campo, uma fecunda área de aproximação com outras ciências, como economia, história, psicologia, geografia, educação, direito e comunicação. Inseparável da prática social, a pesquisa sobre o trabalho torna-se relevante não somente no âmbito acadêmico e na dimensão teórico-metodológica, mas também às ciências aplicadas, pois concerne ao planejamento social e à formulação de diversas políticas públicas, como as de renda, trabalho, emprego, educação, segurança e saúde. Assim, a relação entre políticas públicas, gênero e trabalho, contemplada no presente dossiê, engendra múltiplas possibilidades de apreender fenômenos e situações sociais emergentes no mundo contemporâneo, como a feminização em alguns setores de trabalho, as questões de gênero e sexualidade nas relações de trabalho, a sociedade de serviços e o trabalho imaterial. Conduz também a novas perspectivas de análise de questões tradicionais na sociologia do trabalho, como trabalho doméstico e domiciliar, tempo e condições de trabalho, informalidade, industrialização, reestruturação produtiva e flexibilização, associativismo, cooperativismo e sindicalismo.

A organização deste dossiê constitui uma iniciativa do Núcleo de Estudos sobre o Trabalho (NEST), criado na Universidade Federal de Goiás em 2006, com a finalidade de agregar institucionalmente atividades voltadas à pesquisa, ensino e extensão referentes ao mundo do trabalho. Os artigos que integram o dossiê foram selecionados entre os trabalhos completos aceitos para publicação no Seminário Políticas Públicas, Gênero e Trabalho, realizado na Universidade Federal de Goiás em maio de 2008. A apresentação dos textos principia com o eixo temático das políticas públicas de trabalho e renda, que inclui três artigos. No primeiro, Política de transferência de renda no Brasil: a experiência do Bolsa Família, Rosa Maria Marques analisa as transferências de recursos do Programa Bolsa Família, desenvolvido pelo governo Lula, nos municípios brasileiros, levando em conta variáveis como localização geográfica, porte populacional; nível de pobreza; atividade econômica predominante e relação entre população urbana e rural. Rosa Maria, que coordenou uma pesquisa realizada para o Ministério do Desenvolvimento Social e Combate à Fome em 2006 sobre o progra- 
ma Bolsa Família, compara a destinação de seus recursos com outras transferências de renda promovidas em nível federal desde o governo Collor, ressaltando conseqüências sociais proximamente vinculadas à sua realização, como a multiplicação de negócios e empreendimentos locais. O programa acarreta outras conseqüências indiretas, embora não menos importantes, como a rearticulação do espaço doméstico com a viabilidade de realização de atividades remuneradas, geralmente por mulheres, já que se tornou viável a emancipação social, pelo menos em algum grau, de famílias em situação de miséria ou pobreza.

A condição de baixa renda ou até de ausência de renda constitui um demarcador para o acesso a diversas políticas públicas, como a Previdência Social, salientam Eliane Romeiro Costa e Giovana Guimarães de Miranda no artigo Proteção previdenciária , gênero e renda na idade avançada. Criticando as alterações estruturais do sistema previdenciário que acabam por reduzir o usufruto dos direitos sociais a poucos e excluir aqueles não cobertos pelas políticas assistenciais de combate à pobreza e à miséria, as autoras nos levam a refletir sobre medidas corretivas a desigualdades de acesso à seguridade social derivadas de diferenças biológicas e socioculturais a que se conferiu guarida institucional e normativa.

$\mathrm{O}$ artigo de Cleonice Borges de Souza destaca as políticas públicas voltadas ao desenvolvimento da agricultura familiar, analisando o papel dos Conselhos Municipais de Desenvolvimento Rural Sustentável (CMDRS), criados por demanda do Programa Nacional de Fortalecimento da Agricultura Familiar (PRONAF), instituído pelo Governo Federal em 1996. Analisam-se as relações sociais entre os diversos agentes que interagem no espaço social dos Conselhos, com destaque às relações de gênero, já que há predominância de homens agricultores. O objeto empírico da pesquisa foi o conjunto de quatorze municípios que compõem o Território Estrada de Ferro (TEF), no Estado de Goiás, no qual se elegeu como amostra as cidades de Bela Vista de Goiás e Silvânia. A autora procurou interpretar as relações de poder que se estabelecem nos CMDRS, pesquisando as ações e situações vivenciadas pelos agentes envolvidos, mediante o emprego de técnicas quantitativas e qualitativas. A análise recorre ao conceito de capital social para identificar e mensurar a participação nos Conselhos.

Os limites das políticas públicas de habitação e das ações de movimentos sociais na efetivação de direitos humanos,como o de moradia, constituem o objeto do artigo Direitos humanos, violência, moradia: dignidade ameaçada, de autoria de Solange M. O. Magalhães e Irismar Sousa de Menezes. Parte-se de uma ordem de despejo executada em 2007 pela Subprefeitura de São Paulo, na Favela Boqueirão, para analisar as ações da população local, de órgãos públicos, como o Ministério das Cidades, e a atuação do Movimento dos Trabalhadores Sem-Teto, da Pastoral Social das Irmãs Dominicanas e da Associação de Mulheres do bairro em relação a questões de direitos humanos, moradia, violência, gênero e trabalho.

O artigo de Adriana Piscitelli traz uma importante contribuição neste dossiê, no que se refere propriamente às teorias de gênero. Constatando uma linha crítica, de matiz desconstrutivista, da noção de gênero, que inclui os textos clássicos de Joan Scott, Marilyn Strathern, Donna Haraway e Judith Butler e a contribuição dos estudos feministas, a autora argumenta que tal linha não levou em conta, de maneira expressiva, outras diferenças, além da sexual, Adriana propõe trabalhar com categorias de articulação ou interseccionalidades, 'ferramentas analíticas para apreender a articulação de múltiplas diferenças e desigualdades'. Trata-se de saltar a um nível epistemológico mais elevado, utilizando a própria diferença como categoria analítica, 
o que permite pensar não só as próprias diferenças, mas suas interrelações ou articulações, como gênero-classe, gênero-raça, gêneropoder-sexualidade e outras. Após justificar e construir um referencial teórico relacionado à interseccionalidade, a autora o emprega na análise da identidade e da experiência de mulheres brasileiras migrantes no mercado de trabalho global.

Um segundo grupo de artigos dirige-se à temática das profissões e ocupações. Em O profissionalismo e a construção do gênero na advocacia paulista, Maria da Gloria Bonelli e Rennê Martins Barbalho analisam as diferentes formas de construção de gênero no campo profissional jurídico sob o efeito da progressiva participação da mulher na advocacia brasileira, a partir de 1970 . A pesquisa empírica, realizada de 2006 a 2007, recorreu a dados do Centro de Estudos das Sociedades de Advogados na cidade de São Paulo e a entrevistas qualitativas com advogados e advogadas do interior e da capital do estado de São Paulo. Identifica-se a construção de um script sexuado na carreira, com distinção entre a competência profissional 'natural' dos homens e a capacidade adquirida que requer demonstração, por parte das mulheres, que é contraposta a uma ideologia de neutralidade que caracteriza o profissionalismo e a expertise.

$\mathrm{O}$ artigo seguinte, Trabalho e gênero nas interações de serviços, tem como objeto o serviço em ocupações em que há interação direta entre trabalhadores e clientes. Jordão Horta Nunes, Lúbia Gonzaga Dutra e Marina Lemes Landeiro procuram destacar as distinções de gênero nas interações em serviços, com base em conceitos e perspectivas de análise que orientam a discussão na área: descrição e organização do trabalho, expropriação do 'trabalho emocional' dos trabalhadores; estratégias discursivas de negociação e enfrentamento diante de situações de dominação ou de representações sociais negativas sobre ocupações subalternas. Duas classes de ocupações foram investigadas, empregando técnicas quantitativas e qualitativas: trabalhadores em estabelecimentos de uma rede de fast food em shopping centers e mototaxistas em pontos e agências, na cidade de Goiânia.

O texto de Aldo Antonio de Azevedo, A imaterialidade do trabalho do jogador de futebol: uma interpretação teórica, encerra o grupo de artigos sobre profissões e ocupações. A atividade do jogador de futebol é analisada recorrendo ao conceito de trabalho imaterial, com base em autores como André Gorz, Negri; Lazzarato e outros. Embora a habilidade física seja componente fundamental do reconhecimento e da identidade de um jogador de futebol, o trabalho imaterial aparece na dimensão afetiva e cooperativa da atuação na equipe, na técnica que inclui inteligência e estilo e, sobretudo, na imagem que produz de si mesmo, veiculada pela mídia no contexto de produção de um espetáculo a ser consumido. A esfera midiática que circunscreve o futebol como esporte competitivo constitui, argumenta o autor, a base exterior do trabalho imaterial do jogador de futebol, orientando sua carreira e a possibilidade de sucesso no mercado de trabalho.

O papel dos movimentos sociais e de empreendimentos solidários na construção de alternativas na organização do trabalho e da produção é discutido no artigo de Jaqueline Pereira de Oliveira, Mulheres na economia solidária: possibilidade de reconhecimento e emancipação social. Num contexto de precarização das formas contratuais e de exploração predatória da força de trabalho nas extremidades das cadeias produtivas, a organização de empreendimentos solidários, de forma autogestionária ou intermediada por movimentos sociais ou políticas públicas governamentais, constitui uma alternativa mais propícia à emancipação de grupos sociais excluídos, em relação à pura informalidade. 
Jaqueline analisa o associativismo nos empreendimentos solidários não apenas como forma alternativa para geração de renda e trabalho, mas em sua importância na constituição do self e no desenvolvimento de ações coletivas com participação efetiva e democrática.

A problemática geracional reaparece no artigo de Ana Júlia Rodrigues do Nascimento e Francisco Chagas Evangelista Rabêlo, Memória e envelhecimento: narrativas sobre questões de gênero e do mundo do trabalho. O texto traz considerações a respeito de mudanças sociodemográficas na composição da população brasileira e sobre memória, envelhecimento e narrativas, com suporte em referências clássicas e na literatura recente. Numa segunda parte, são analisados diversos depoimentos de idosos, com destaque para as narrativas sobre experiência de trabalho e representações sobre o trabalho orientadas por gênero. Merece destaque a análise das considerações dos entrevistados a respeito das políticas públicas de previdência social e seus efeitos na prática cotidiana.

Concluímos o dossiê com temáticas clássicas e de grande importância no mundo industrial: a divisão do trabalho e o controle do processo e da produção. Sônia Aparecida Lôbo, em seu artigo Das formas de controle e disciplinarização à resistência operária no cotidiano fabril: o trabalho na indústria farmacêutica, investiga diversas atividades e procedimentos relacionados ao controle na indústria - rotinização de tarefas, controle de qualidade, controle sanitário, equipamento de proteção industrial, ergonomia - bem como uma crítica dirigida aos limites e à falta de efetividade das medidas de controle e de segurança na fábrica, apontando fatores como desqualificação dos funcionários, falta de treinamento, precarização das relações de trabalho, rotatividade e autoritarismo. A autora ressalta a contradição entre um discurso que justifica o controle rigoroso sobre as atividades e a qualidade do produto, bem como a distinção entre administração e produção, remanescente do taylorismo na organização do trabalho, pelo apelo ao motivo da 'construção da saúde da população'. O descumprimento das normas sanitárias pela própria empresa e a ocorrência de doenças ocupacionais e de acidentes de trabalho conduzem a práticas de resistência entre os trabalhadores das duas indústrias pesquisadas, que integram o pólo farmacêutico existente no eixo Goiânia/Anápolis.

Esperamos que esta apresentação tenha propiciado aos interessados na análise de políticas públicas, gênero e trabalho uma visão preliminar dos textos que integram a compilação, motivando à leitura deste dossiê para a qual temos o prazer de convidá-los. 